\title{
Afectación a las exportaciones de banano ecuatoriano a causa de la pandemia por el covid 19
}

\section{Impact on Ecuadorian banana exports due to the covid 19 pandemic}

DOI: $10.46932 / \mathrm{sfjdv2n2-158}$

Received in: March 1st, 2021

Accepted in: May 30th, 2021

Ing. Com. Guido Homero Poveda Burgos

Magister en Administración y Dirección de Empresas

Docente de la Universidad de Guayaquil

E-mail: guido.povedabu@ug.edu.ec

Lcda. Com. Ext. Clara Augusta Cabrera Jara

Magister en Administración y Dirección de Empresas

Docente de la Universidad de Guayaquil

E-mail: clara.cabreraj@ug.edu.ec

Ing. Com. Jean Steve Carrera López

Magister en Administración de Empresas Mención Negocios Internacionales

Docente de la Universidad de Guayaquil

E-mail: jean.carreralo@ug.edu.ec

Ing. Com. Bárbara de Lourdes Sambonino García

Magister en Comercio Exterior mención Gestión Aduanera

Docente de la Universidad de Guayaquil

E-mail: loudes.samboninog@ug.edu.ec

\section{RESUMEN}

En los actuales momentos, el desarrollo económico del Ecuador se encuentra seriamente comprometido ante la declaración de la pandemia a causa del COVID19, por cuanto las medidas de bioseguridad adoptadas obligan al confinamiento de los habitantes en sus hogares, y una seria reducción de la capacidad empresarial y productiva de todos los sectores. Las generalidades en el comportamiento de la economía reflejan una perspectiva global muy compleja en el sector bananero del país, por cuanto desde el pequeño productor independiente hasta las grandes empresas nacionales y transnacionales dedicadas a la producción y comercialización de la fruta se ven seriamente afectados en toda su cadena logística. Las operaciones de comercio internacional, así como el consecuente impacto al medio ambiente se ha reducido significativamente en todos sus indicadores, afectando el ingreso de divisas, liquidez del sistema financiero, estabilidad de personal, pago de proveedores y otros.

Es de recordar que el banano representa uno de los principales recursos renovables que posee el Ecuador dentro de su oferta exportable tomando en cuenta que según la Asociación de Exportadores de Banano del Ecuador los envíos al exterior crecieron un 4\% durante el primer semestre 2019 representando 1706 millones de dólares que se inyectan directamente a la economía nacional. La oferta exportable del banano se ha reducido aproximadamente un $70 \%$ en los mercados internacionales y a su vez también se han incrementado el precio de los servicios logísticos multimodal requeridos para el transporte de la fruta por el riesgo inherente a un contagio no deseado que conlleva en los actuales momentos el desarrollo de toda actividad comercial.

En la planificación de la política pública ecuatoriana, está muy presente que el banano tiene un importante aporte a la economía fundamental del Ecuador. Dándole la debida importancia siendo el banano la 
segunda fuente de ingresos al estado. Constituyéndose este en un elemento clave de la economía ecuatoriana.

Palabras clave: Desarrollo económico, perspectiva global, comercio y medio ambiente, recursos renovables, oferta, política pública

\begin{abstract}
At the present time, the economic development of Ecuador is seriously compromised by the declaration of the pandemic caused by COVID19, since the biosecurity measures adopted force the confinement of the inhabitants to their homes, and a serious reduction of the business and productive capacity of all sectors. The general economic performance reflects a very complex global perspective in the country's banana sector, since everything from small independent producers to large national and transnational companies engaged in the production and marketing of the fruit are seriously affected throughout the logistical chain. International trade operations, as well as the consequent impact on the environment, have been significantly reduced in all indicators, affecting the income of foreign currency, liquidity of the financial system, stability of personnel, payment of suppliers and others. It should be remembered that bananas represent one of the main renewable resources that Ecuador has within its exportable supply taking into account that according to the Association of Banana Exporters of Ecuador, shipments abroad grew by $4 \%$ during the first half of 2019 representing US $\$ 1706$ million that are directly injected into the national economy. The exportable supply of bananas has been reduced by approximately $70 \%$ in international markets and at the same time the price of multimodal logistics services required for the transportation of the fruit has also increased due to the inherent risk of an unwanted contagion that the development of any commercial activity entails at the present time. In the planning of the Ecuadorian public policy, it is very present that the banana has an important contribution to the fundamental economy of Ecuador. Giving it due importance being the banana the second source of income to the state. This is a key element of the Ecuadorian economy.
\end{abstract}

Key words: Economic development, global perspective, trade and environment, renewable resources, supply, public policy.

\title{
1 INTRODUCCIÓN
}

La exportación de banano representa el segundo rubro no petrolero de la oferta exportable del Ecuador, ligando a miles de productores de las provincias de Guayas, Manabí, El Oro, Esmeraldas, Los Ríos y parte de Santo Domingo de los Tsáchilas. De esto se puede observar que la provincia de El Oro cuenta con la mayor cantidad de haciendas a escala nacional, con 2375 de las 5737 que registra la Subsecretaría de Comercialización del Ministerio de Agricultura, es decir, el 41,39\%. La mayoría de esos predios está en manos de los pequeños y medianos productores.

Para los agricultores orenses, el cultivo del banano ha sido favorecido por las excelentes condiciones climáticas y ecológicas de la llanura occidental de la provincia fronteriza, las principales áreas de cultivo están en los cantones Machala, Pasaje, Santa Rosa, Arenillas y El Guabo. En el mapa de producción nacional, Los Ríos es la provincia que concentra el 40\% de la fruta, le siguen Guayas con un 
$32 \%$ y El Oro que se sitúa tercera con el 27\%, según la Asociación de Exportadores de Banano del Ecuador (AEBE).

\section{HISTORIA EN EL ECUADOR}

Según las más viejas estadísticas, se conoce que el Ecuador se inició en la exportación de banano en el año 1910, año en que se informa exporto 71.617 racimos de más de 100 libras. El Estado Ecuatoriano ha intervenido en la actividad bananera desde que inicia el cultivo en gran escala.

En Ecuador, la verdadera comercialización bananera se inicia en la década de 1950, aunque en la Provincia de El Oro se tiene registro de su producción desde 1925 comercializando hacia los mercados de Perú y Chile.

En los primeros años el comercio del banano constituía un riesgo por la carencia de las vías de comunicación, no disponíamos de carreteras, lo poco que se recolectaba de las fincas procedentes de cultivos de carácter domestico se lo transportaba en acémilas hasta las estaciones ferroviarias y por vía fluvial hasta los puertos de embarque.

Sin embargo, el Ecuador ostento una posición de liderazgo en el mercado internacional, llegando a representar la cuarta parte del total del volumen comercializado. El crecimiento vertiginoso de la producción y exportación bananera se explica por las altas ventajas competitivas que ofreció el país frente a Centroamérica cuando se presenciaba el mal de Panamá y de huracanes causaron estragos en las plantaciones de estas zonas. En el Ecuador la incidencia de las plagas y enfermedades sea incipiente por el bajo desarrollo de la producción, y el clima es mucho más benigno. Las ventajas naturales que ofreció el Ecuador se fortalecieron con la intervención del Estado con medidas que apoyaban la actividad privada. El impulso más importante fue seguramente la construcción vial y portuaria necesaria para transportar un producto rápidamente perecedero. Se construyeron grandes vías de comunicación que unían las zonas bananeras que inicialmente estaban aisladas, como el caso de carreteras Santo Domingo - Quevedo; Santo Domingo - Esmeraldas; Duran Tambo; Boliche - Naranjal - Machala, y unas tantas carreteras más de segundo orden que poco a poco fueron formando la gran red vial que actualmente tiene el Ecuador a lo largo de la costa, donde se encuentran sembradas las plantaciones de banano.

En el año 1955 se crea la Asociación Nacional de Bananeros del Ecuador (ANBE) con sede en Guayaquil, con la finalidad de dar atención y resolución a todos los problemas relativos a la producción, comercio e industrialización del banano.

Entre otras de las funcione encomendadas fueron, determinar las áreas aptas para el cultivo, construcción de drenajes en las zonas bananeras, apertura de vías de comunicación control fitosanitario 
contra plagas y enfermedades, y defensa de los precios tanto en el país como en el extranjero, a través de las compañías exportadoras. Para entonces a finales del año 1955se registraba una exportación de 808.600 T.M. que representa el $28 \%$ de la exportación de esta fruta a nivel mundial. La enfermedad de la sigatoka que desde el año 1950 había llegado a la provincia de Esmeraldas se fue propagando descontroladamente, lo que preocupo mucho a los bananeros y acudieron al Estado con el fin de crear lo que fue Campaña de Defensa del Banano, Institución adscrita a ANBE, que se encargaría a través de su personal técnico del control de plagas y enfermedades del banano; fue financiada de una tasa que se cobraría por racimo exportado. En el año en cuestión, se inicia un registro exacto de las áreas de banano sembradas en el país con el fin de poder planificar las campañas fitosanitarias.

En ese entonces y hasta el año 1966, sólo producíamos la variedad Gros Michel y fue extraordinario el desarrollo de ese cultivo, que a esa fecha llegaron a tener registradas 163.772 Has. En plena producción, sembradas a lo largo y ancho de nuestro litoral, desde la provincia de Esmeralda en la frontera con Colombia, hasta la Provincia de El Oro en la frontera con el Perú, con una producción en no menos de 80 millones de racimos, de los cuales sólo exportamos más o menos el 43\%, el retro en mínimos porcentajes se destinaba para el consumo interno de nuestra población, para alimento animal o materia prima para una incipiente industrialización, más de un 40\% se perdió en las bananeras.

Recién a mediados de los 70 el Estado Interviene directamente, cuando se crea el Instituto Nacional de Investigaciones Agropecuaria (INIAP) donde empiezan con el estudio de las enfermedades que bajaban la producción del banano, teniendo como una base de estudio en Machala.

\section{APORTE EN NUESTRA ECONOMÍA}

La actividad del banano en el Ecuador desde hace sesenta años ha tenido y tiene un peso importante en el desarrollo del país, tanto desde el punto de vista económico como social. En lo económico por su participación en el PIB y en la generación de divisas y en lo social por las fuentes de empleo que genera y más aún por su peso importante en determinadas regiones de la costa ecuatoriana.

Exportaciones bananeras del Ecuador - 1er Semestre 2019

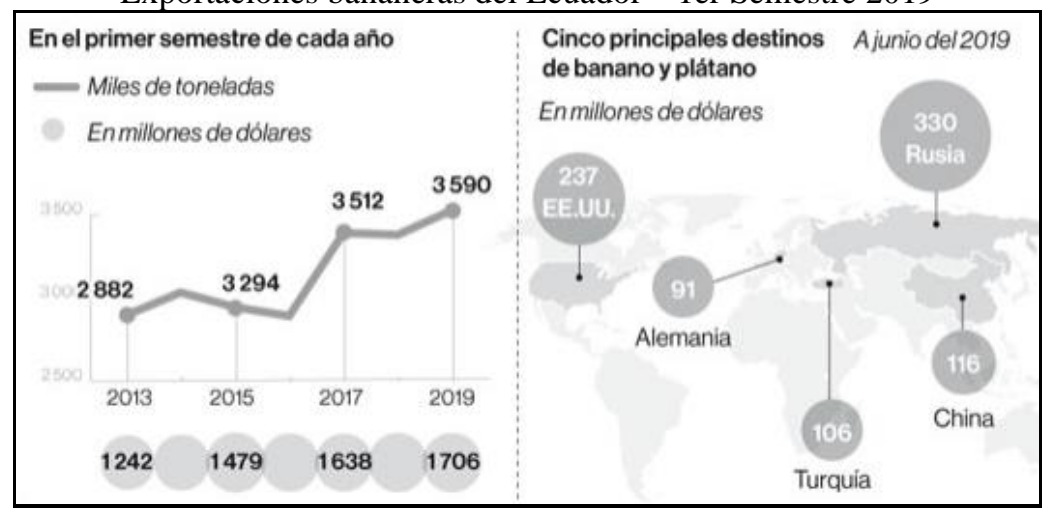

Fuente: Asociación de Exportadores de Banano del Ecuador 
El desarrollo de la actividad bananera ha estado muy vinculada a la iniciativa privada de los ecuatorianos que han invertido su capital tanto económico como humano a las actividades de producción y exportación de la fruta, y ha recibido la valiosa contribución de capitales internacional que ha permitido que el Ecuador sea el primer país exportador de banano en el mundo con aproximadamente un 30\% de la oferta mundial, seguidos por Costa Rica, Filipinas y Colombia, juntos abastecen más del 50\% del banano consumido en el mundo.

Pero al ser una actividad vinculada directamente al mercado internacional no está ajena a las dificultades que la propia competencia genera, a las disciplinas tanto comerciales como técnicas impuestas por los países compradores, a las condiciones de comportamiento de la naturaleza y a las condiciones económicas y políticas internacionales.

El presidente de entonces, promovió activamente la expansión de los cultivos y el desarrollo de este nuevo rubro de exportación. Cuando asume la presidencia en 1948 el Ecuador exportaba 3.8 millones de racimos y al concluir en 1945 llegó a los 16.7 millones, lo que representa un crecimiento del $421 \%$, porcentaje que prácticamente no tiene comparación en ningún otro período de la expansión bananera del país en una declaración de buenos principios, que sirven para tranquilizar la conciencia y pensar que ya se está haciendo algo: la contribución al desarrollo sostenible debe implicar un cambio en la visión del planeta, que moralmente se traduzca en un cambio de actitudes y de conducta.

\section{EXPORTACIÓN BANANERA 2019}

A 1 final del 2019, la exportación de banano de nuestro país nuevamente creció en 1,78\%. Este es el nivel más bajo desde el 2016. A diciembre del 2019, se embarcaron 356 millones 825 mil 216 cajas de banano de 43 libras, un 1,7\% más que en igual período del 2018. El crecimiento en el 2018 fue de 7,4\% y durante el 2017 fue de 2,29\%. Esto implica que, en términos globales durante el 2019, la exportación de banano experimentó un estancamiento.

- Las condiciones climáticas presentadas en el tercer trimestre del 2019

- Las manifestaciones de octubre que incidieron negativamente en la actividad de embarque.

- La reducción en el embarque de cajas de 43 libras

\section{A ESTO SE AÑADEN FACTORES EXTERNOS COMO:}

Una mayor preferencia por otras frutas como en el mercado de los Estados Unidos de América, como el aguacate

La fuerte reducción de compra por parte de la Unión Europea 
El estancamiento de la importación de mercados "tradicionales" como los Estados Unidos de América, Rusia y el Cono Sur

\section{FRENTE A ELLO, EL BANANO ECUATORIANO ENCONTRÓ ESCENARIOS}

\section{FAVORABLES EN:}

Asia: por el incremento de compra de China y Asia

África: el incremento de compra por parte de Argelia

Medio Oriente: por los envíos declarados en origen hacia Turquía pero que después se trasladan hacia otros puertos de la región

Europa Este: por un incremento de la demanda en las ex repúblicas soviéticas, incluida Ucrania

EFTA: Por el incremento de los embarques hacia Noruega

El crecimiento de los envíos de la caja 208 por el aumento de la demanda de China y Medio Oriente

\begin{tabular}{|c|c|c|c|}
\hline PAÍS & 2018 & 2019 & $\begin{array}{c}\text { Variación } \\
2019-2018 \\
\%\end{array}$ \\
\hline EE.UU. & $35 ' 539.293$ & 37005.648 & 4,13 \\
\hline UNIÓN EUROPEA & 115350.751 & $98^{\prime} 421.985$ & $-14,68$ \\
\hline RUSIA & $77 / 295.300$ & $75{ }^{\prime} 533.502$ & $-2,28$ \\
\hline MEDIO ORIENTE & $48^{\prime} 579.440$ & $53^{\prime} 082.661$ & 9,27 \\
\hline CONO SUR & $25^{\prime} 188.783$ & $23^{\prime} 327.612$ & $-7,39$ \\
\hline EUROPA ESTE & $14^{\prime} 939.175$ & 177585.510 & 17,71 \\
\hline AFRICA & $7 ' 287.653$ & $16^{\prime} 906.593$ & 131,99 \\
\hline ASIA & $21 \% 350.954$ & $29 \times 449.473$ & 37,93 \\
\hline OCEANÍA & 3701.181 & 3769.547 & 1,85 \\
\hline OTROS (EFTA) & 1329.638 & 17742.685 & 31,06 \\
\hline TOTAL & $350^{\prime} 562.168$ & $356^{\prime} 825.216$ & 1,79 \\
\hline
\end{tabular}

Fuente: Asociación de Exportadores de Banano del Ecuador

\section{COMPORTAMIENTO DE LOS MERCADOS DE DESTINO DEL BANANO ECUATORIANO DURANTE EL 2019}

Estados Unidos de América: De acuerdo a los registros de embarque, existió un crecimiento del $4,13 \%$, generado especialmente por los envíos hacia la costa oeste de ese mercado, donde el aumento fue de $5,45 \%$. Pero este aumento no ha sido lo suficiente para aumentar significativamente nuestra. 
participación. Según el Departamento de Agricultura de los Estados Unidos de América, a diciembre del 2018, nuestro banano captó el 14,02\% de ese mercado, mientras que, para igual período del 2019, la participación subió al 14,39\%. Hay que tomar en consideración que la llegada de banano a ese mercado hasta diciembre del 2019 ha sido un 2,12\% menor que en el 2018.

Unión Europea: Los embarques a este mercado cayeron fuertemente durante el 2019 (14,68\%). La causa principal fue la reducción de los envíos a cuatro países de esa zona que eran abastecidos sustancialmente por el Ecuador: Alemania, Bélgica, Italia y Polonia.

Comparativo por destino $2019-2020$ WK 13

\begin{tabular}{|l|r|r|r|}
\hline \multicolumn{1}{|c|}{ DESTINO } & \multicolumn{1}{c|}{ CAIAS 2019 } & \multicolumn{1}{c|}{ CAIAS 2020 } & VARIACION 2020/2019 \\
\hline EE.UU PACIFICO & $7,148,337.00$ & $6,664,528.00$ & $-0.8 \%$ \\
\hline EE.UU ATLANTICO & $3,230,006.00$ & $3,081,253.00$ & $-4.6 \%$ \\
\hline UE NORTE & $19,057,369.00$ & $21,583,706.00$ & $13.3 \%$ \\
\hline UE MEDITERRANEO & $9,361,966.00$ & $10,907,697.00$ & $16.5 \%$ \\
\hline EUROPA EFTA & $438,636.00$ & $537,556.00$ & $22.6 \%$ \\
\hline RUSIA & $22,110,391.00$ & $22,003,173.00$ & $-0.5 \%$ \\
\hline EUROPA ESTE & $4,626,045.00$ & $5,722,314.00$ & $23.7 \%$ \\
\hline CONO SUR & $5,562,982.00$ & $5,892,299.00$ & $5.9 \%$ \\
\hline AFRICA & $2,864,386.00$ & $4,044,287.00$ & $41.2 \%$ \\
\hline MEDIO ORIENTE & $12,396,467.00$ & $15,847,985.00$ & $27.8 \%$ \\
\hline ASIA & $7,395,005.00$ & $5,885,069.00$ & $-20.4 \%$ \\
\hline OCEANIA & $1,053,303.00$ & $899,949.00$ & $-14.6 \%$ \\
\hline TOTAL & $\mathbf{9 5 , 2 4 4 , 8 9 3 . 0 0}$ & $\mathbf{1 0 3 , 0 6 9 , 8 1 6 . 0 0}$ & $\mathbf{8 . 2 \%}$ \\
\hline
\end{tabular}

Fuente: Foro bananero ecuatoriano 2020

La fluctuación de las exportaciones de banano ecuatoriano, han venido presentando leves fluctuaciones respecto al total de cajas, viéndose una marcada reducción de este en el Asia y Oceanía, donde según reportes de la Asociación de Exportadores de Banano del Ecuador, con la declaración de la pandemia a causa del COVID19 estas cifras tienen tendencia a incrementarse ante la paralización de los mercados, cierre de puertos, y alto costo de movilización de cargas por parte de líneas navieras y armadores.

La reducción de los envíos a la zona mediterránea de la Unión Europea fue mayor (29,76\%) que lo sucedido con los envíos a la zona norte (6,34\%). La razón fue la baja de la importación de banano en esta zona, a lo que se suma el incremento de banano procedente de países que durante el 2019 tenían una participación baja: Guatemala, Panamá. También y como pasó en el mercado de EE.UU., la preferencia del banano fue desplazada por otras frutas, especialmente, aguacate.

Rusia: El desempeño en este mercado también fue negativo (2,28\%), aunque viéndolo de manera positiva, se puede decir que el mercado tuvo un estancamiento. Las propias cifras de la oficina estadística 
rusa señalan que, hasta diciembre del 2019, la importación total se redujo 2,94\% en comparación al 2018. Hay que destacar que el rublo ha recuperado posición frente al dólar estadounidense, por lo que también se puede afirmar que el mercado ruso está llegando a su techo de consumo de banano.

Medio Oriente: Por tercer año consecutivo, este mercado presenta un desempeño positivo, un crecimiento cercano al 10\%. El destino del principal empuje en esta región fue Turquía (un crecimiento de 52\%). Sin embargo, hay que señalar que este mercado es una especie de bisagra para transferir la fruta a otros mercados. Además, el ingreso directo de banano ecuatoriano en Turquía durante el 2019 se redujo en $21 \%$. Un destino donde se redujo de manera importante los envíos de banano fue Arabia Saudita (22\%). Frente a ello, los envíos de banano a Irak crecieron 81\%. Una parte de ello debieron trasladarse a Irán, debido a las medidas económicas que impuso los EE.UU. y que afectan a las navieras. En esta zona, nuestro principal competidor es Filipinas.

Cono Sur: El desempeño fue muy negativo en este mercado. La causa fue el problema económico de Argentina y Chile. En Argentina por los problemas estructurales de su economía y en Chile, por la reducción de sus exportaciones de cobre, especialmente al mercado asiático. A esto se suma, los dos meses de protestas en Chile que influyeron en la cotización del peso chileno. Estos dos mercados constituyen el 90\% del total de banano que se importa en esa región. Los envíos hacia Argentina disminuyeron 14,24\%, mientras que la exportación a Chile se mantuvo casi igual a la del $2018(-0,59 \%)$.

Europa Este: Este ha sido uno de los mercados que también tuvo un buen desempeño durante el 2019. Es una zona en la cual el Ecuador es un proveedor sustancial. Además, no experimentó desequilibrios económicos y políticos, y el problema de Crimea se mantuvo en una situación estable, lo que permitió que Ucrania incremente las compras de banano de manera general, y de ello aprovechó el Ecuador. Los envíos a Ucrania se incrementaron en un nivel cercano al 20\%. El área comprendida cerca al Mar Negro y que fueron ex repúblicas soviéticas también aumentaron sus compras: Kirguistán, Kazajistán, Turkmenistán, Uzbekistán. A estos países se está llegando de forma directa más que en el 2018.

África: Es la zona de mayor crecimiento para la exportación ecuatoriana de banano. El motor de este desempeño por volumen fue Argelia; en el 2018 el volumen enviado a ese país fue de 3,5 millones de cajas, para el 2019, esta cantidad subió a 13 millones de cajas. Los otros destinos: Marruecos, Túnez y Sudáfrica decrecieron su compra de banano.

EFTA: El crecimiento del 31,06\% antes de la vigencia del Acuerdo de Libre Comercio, promete mejores posibilidades de desempeño futuro en ese mercado. 
Importancia de cada mercado $2019-2018$
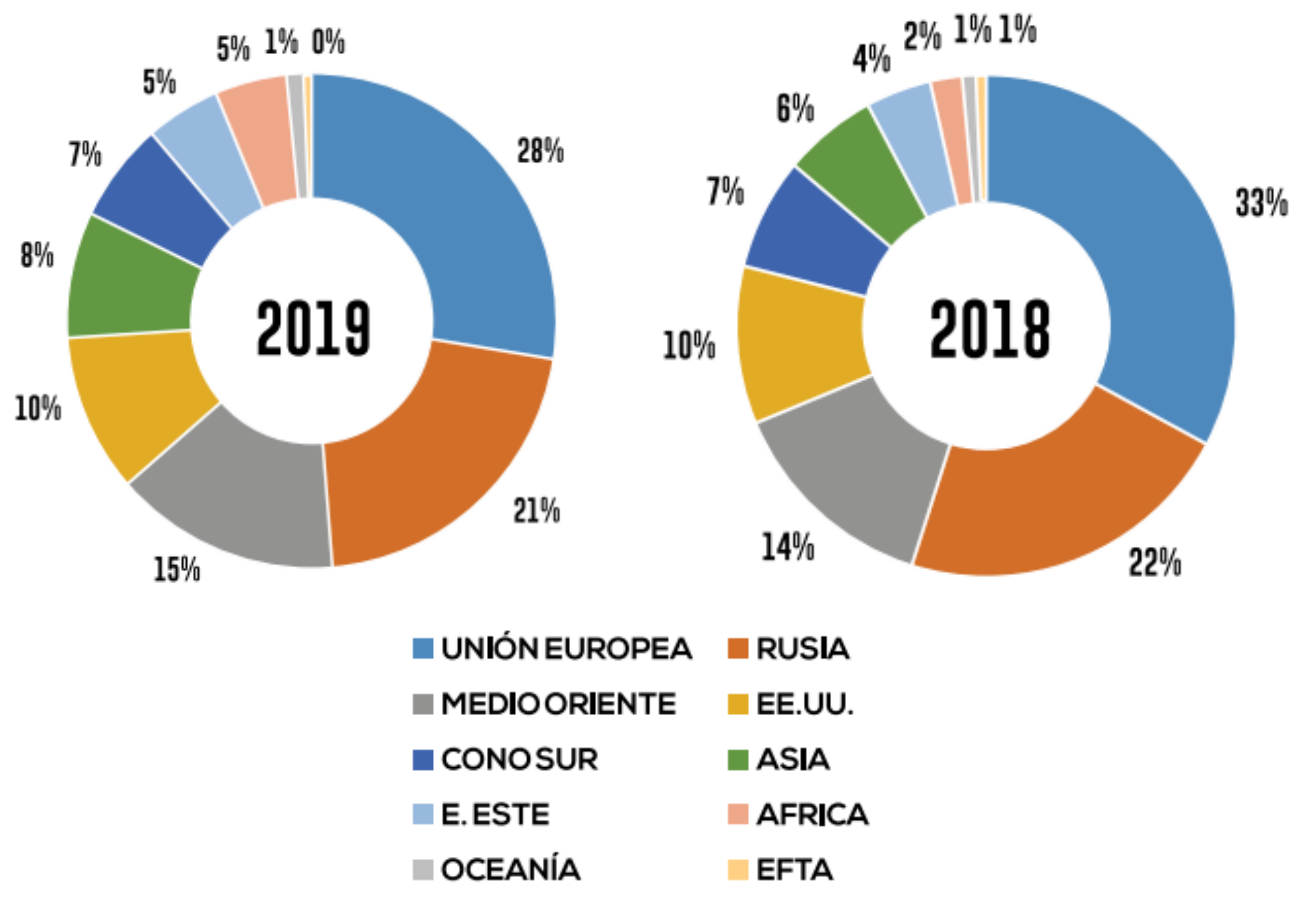

Fuente: Proecuador

\section{TAXONOMÍA DEL COVID19, SU PRESENCIA EN ECUADOR Y EL MUNDO}

Ecuador, así como el resto del mundo se ha visto seriamente afectado por este nuevo virus denominado COVID19 que ha golpeado la economía nacional e internacional, afectando principalmente el sistema respiratorio, la constitución de este no sólo es compleja, sino que tiene un alto grado de contagio y no se conoce del desarrollo de inmunidad ante el mismo. Romero, J., Agnetti, C., Coral, A., \& Medrano, A (2020) mencionan:

Los virus están clasificados como microorganismos, junto con las bacterias, hongos y levaduras y los parásitos. Sin embargo, los virus no son considerados actualmente seres vivos como los otros microorganismos, son entidades químicas con actividad biológica. Poseen un solo tipo de ácido nucleico de pequeño tamaño con respecto a otros agentes biológicos, rodeado por una cáscara o cápside formada por numerosas copias de una proteína o de un número limitado de ellas. Algunos grupos de virus presentan por fuera de la cápside una envoltura lipídica de origen celular en la que se insertan glicoproteínas. No presentan sistemas enzimáticos propios, por tanto, no son capaces de replicarse por sí solos y requieren de células animales, vegetales o bacterias para cumplir su ciclo de reproducción.

El nuevo virus aislado del tracto respiratorio inferior de pacientes en Wuhan, China, y a partir del análisis de su secuencia genética y homología reveló que presenta muchas similitudes con el coronavirus del síndrome respiratorio agudo severo (SARS-CoV) y ha sido clasificado como beta-coronavirus, denominándose SARS-CoV-2 por el Comité Internacional de Taxonomía de Virus (ICTV). Más 
específicamente, el SARS-CoV-2 está conformado por un núcleo de ARN (cadenas monocatenarias de ácido ribonucleicos responsables de la carga viral del material genético), una membrana externa protectora de lípidos (bicapa lipídica) y finalmente tiene localizado proteínas transmembrana (glicoproteína viral "S" ricamente glicosilada y " $\mathrm{M}$ " proteína matricial localizada en el interior de la envoltura), siendo estas las que ofician de "agentes colonizantes" de las células sanas. La neumonía causada por la infección viral fue llamada COVID-19, es una zoonosis que parece haberse originado en murciélagos y transmitido a los humanos a través de mutaciones del virus en uno o varios huéspedes intermedios que al momento no se han identificado. Lo que se ha podido identificar es que entre las vías principales de transmisión entre humanos se encuentra el contacto, por aire en el aliento o las mucosas y a través de la ruta fecal-oral. Este virus tiene una alta capacidad de contagio, mayor que la de la mayoría de virus conocidos y dado que es nuevo nadie ha podido desarrollar inmunidad en el pasado. (p. 21)

\section{AFECTACIÓN ECUADOR - LATINOAMÉRICA}

Definitivamente el mercado internacional de los productos tradicionales y no tradicionales ecuatorianos está seriamente afectado, pues este no sólo que se previa un crecimiento máximo del $1 \%$ en el PIB, sino que ahora ante la crisis del COVID19, este causará una caída estrepitosa mayor al $-1 \%$. CEPAL (2020) Indica:

América Latina y el Caribe enfrenta la pandemia desde una posición más débil que la del resto del mundo. Antes de la pandemia, la CEPAL preveía que la región crecería un máximo del 1,3\% en 2020. Sin embargo, los efectos de la crisis han llevado a cambiar esa previsión y pronosticar una caída del PIB de al menos un 1,8\%. Sin embargo, no es de descartar que el desarrollo que la pandemia lleve a previsiones de contracciones de entre un 3\% y un 4\%, o incluso más. El impacto económico final dependerá de las medidas que se tomen a nivel nacional, regional y mundial. (p. 5)

Según Acorbanec 2020, la actividad ha venido trabajando y exportando con normalidad, varios países de Europa han parado sus compras a causa del brote del COVID-19 por inconvenientes en la logística y restricciones en la movilidad y cierre de fronteras.

Se prevé que entre la primera semana de abril 2020 y las próximas dos se reduzca la compra de la fruta en un 20 a $25 \%$, por lo que tendríamos una reducción notable de las exportaciones bananeras”, según datos del sector exportador.

Son 200.000 familias que viven de manera directa del sector bananero que es el que está generando actualmente divisas para el país, se continúa trabajando con todas las medidas de bioseguridad hasta que se pueda manejar los costos para exportación. 


\section{COVID19 Y SU IMPACTO EN LA POLÍTICA FISCAL}

El desarrollo de una política fiscal a la par de la crisis a casa de la pandemia del COVID19 en Ecuador no marcha por buen camino, pues la reducción de las exportaciones de banano y otros productos ha limitado el ingreso de divisas y en una economía que no tiene política es muy complicado y se puede caer en una crisis financiera complicada de sobrellevar. Clavellina Miller, J. L. (2020) indica que:

De acuerdo con Rogoff (2020), pese a los esfuerzos que varias economías desarrolladas han implementado en materia de política fiscal y monetaria, la crisis global actual provocada por los efectos de la pandemia de COVID-19 es la mayor en al menos 150 años. Probablemente no sólo se presente una crisis económica sino también financiera. La recuperación podría ocurrir a partir el cuarto trimestre del año, con niveles productivos que no serán los mismos que los previos a la pandemia, por lo que los daños económicos serán duraderos.

Por su parte, para el FMI (2020) aunque todavía no se conocen con exactitud los alcances y la duración de la crisis, se trata de la mayor crisis económica desde la gran depresión de los 1930, anticipa que este año cerca de 170 países experimentarán una caída en su PIB per cápita. Además, reconoció que las economías en desarrollo en África, América Latina y Asia se encuentran en grave riesgo por contar con sistemas de salud débiles, estar densamente poblados, contar con menores recursos, enfrentar un endurecimiento drástico de las condiciones financieras y, en algunos casos, mostrar un elevado endeudamiento

El propio Fondo señaló que en los últimos dos meses las economías emergentes han observado salidas de capital por alrededor de 100 mil millones de dólares (más de 3 veces comparado con lo ocurrido en la crisis financiera de 2008-2009); que la caída en los precios de las materias primas reducirá el valor de las exportaciones y anticipó una menor recepción de remesas.

Este organismo internacional señala que alrededor del mundo las medidas fiscales contabilizan cerca de 8 billones de dólares y, además, se han implementado medidas masivas de política monetaria por parte de los países del G-20. Anticipó que, incluso si la pandemia cede en la segunda mitad del 2020, el levantamiento gradual de la cuarentena hará que la economía se recupere parcialmente hasta 2021; sin embargo, aceptó que aún existe una elevada incertidumbre sobre la duración de la crisis. Estableció 4 prioridades para atender la situación actual: 1) Continuar con las medidas de contención y de apoyo a los sistemas de salud; 2) Proteger a las personas y empresas afectadas con medidas fiscales y financieras focalizadas y oportunas (entre las que se encuentra el diferimiento del pago de impuestos, subsidios al salario y transferencias en efectivo a los más vulnerables, extensión de los seguros de desempleo y asistencia social, extensión de los plazos a los créditos bancarios y provisión de liquidez al mercado; 3 ) Reducción del estrés financiero e impedir el contagio; y 4) Planear la recuperación, de manera que se 
levanten las restricciones cuidadosamente y se impulse la demanda simultáneamente (en donde las expectativas de inflación se encuentren ancladas la política monetaria podría permanecer laxa). (p. 2)

\section{CONCLUSIONES}

La economía ecuatoriana se encuentra seriamente vulnerada ante la reducción de las exportaciones de banano y su incidencia directamente proporcional al ingreso de divisas para sostener la economía.

Existe un riesgo inherente de cierre y quiebra de muchas empresas relacionadas directa e indirectamente con el negocio bananero.

Los foros de expertos en banano, en los actuales momentos se encuentran buscando estrategias para procurar la reducción de costos y mantener competitividad de mercado ante el incremento de los precios de transporte de fruta en la cadena logística multimodal.

El mundo post-pandemia será muy diferente, dado que habrá mucha gente sensibilizada acerca de la importancia de las buenas prácticas de manufactura. Será una oportunidad única para reforzar la cultura organizacional respecto al manejo de los bienes de adquisición y venta.

La política fiscal y tributaria que se está manejando en los actuales momentos, obliga a repensar el giro de muchas actividades comerciales, por cuanto la afectación financiera afecta con dureza la liquidez empresarial y el sostenimiento de sus operaciones.

Es incierto el sostenimiento del actual modelo productivo de banano en el Ecuador por cuanto muchos pequeños empresarios y agricultores se ven en dificultados financieras para el sostenimiento de sus operaciones.

La mano de obra directa e indirecta relacionada con la actividad exportadora de banano representa el grupo humano más numeroso del Ecuador y este se encuentra en un proceso de contracción muy complejo que no se ha visto desde los primeros inicios de esta actividad empresarial en el año 1925 con Perú y Chile desde la provincia de El Oro, y, desde 1950 con el resto del mundo. 


\section{BIBLIOGRAFÍA}

Asociación de exportadores de banao del Ecuador, 2020

CEPAL, N. (2020). América Latina y el Caribe ante la pandemia del COVID-19: efectos económicos y sociales.

CEPAL, N. (2020). Dimensionar los efectos del COVID-19 para pensar en la reactivación.

Clavellina Miller, J. L. (2020). Política fiscal ante la crisis del COVID-19 en América Latina.

https://elproductor.com/ecuador-se-presume-una-reduccion-de-las-exportaciones-de-banano/

Martínez Soria, J., Torres Ramírez, C., \& Orozco Rivera, E. D. (2020). Características, medidas de política pública y riesgos de la pandemia del Covid-19.

Romero, J., Agnetti, C., Coral, A., \& Medrano, A. RETOS EN LA CADENA DE SUMINISTRO DE ALIMENTOS ASOCIADOS A LA PANDEMIA DE COVID-19. 